\title{
One-Step Electrodeposition of Self-Assembled Colloidal Particles: A Novel Strategy for Biomedical Coating
}

\author{
Jiadi Sun, ${ }^{\dagger}$ Xiaoya Liu, ${ }^{*}{ }^{\dagger}$ Long Meng, ${ }^{\dagger}$ Wei Wei, ${ }^{\dagger}$ and Yufeng Zheng ${ }^{\ddagger}$ \\ ${ }^{\dagger}$ Key Laboratory of Food Colloids and Biotechnology, Ministry of Education, School of Chemical and Material Engineering, Jiangnan \\ University, Wuxi, Jiangsu 214122, People's Republic of China \\ ${ }^{\ddagger}$ State Key Laboratory for Turbulence and Complex System and Department of Materials Science and Engineering, College of \\ Engineering, Peking University, Beijing 100871, People's Republic of China
}

\section{Supporting Information}

\begin{abstract}
A novel biomedical coating was prepared from selfassembled colloidal particles through direct electrodeposition. The particles, which are photo-cross-linkable and nanoscaled with a high specific surface area, were obtained via self-assembly of amphiphilic $\operatorname{poly}(\gamma$ glutamic acid)-g-7-amino-4-methylcoumarin ( $\gamma$-PGA-g-AMC). The size, morphology, and surface charge of the resulting colloidal particles and their dependence on $\mathrm{pH}$, initial concentrations, and UV irradiation were successfully studied. A nanostructured coating was formed in situ on the surface of magnesium alloys by electrodeposition of colloidal particles. The composition, morphology, and phase of the coating were monitored using Fourier transform infrared spectroscopy, energy-dispersive X-ray spectroscopy, scanning electron microscopy, and X-ray diffraction. The corrosion test showed that the formation of the nanostructured coating on magnesium alloys effectively improved their initial anticorrosion proper-

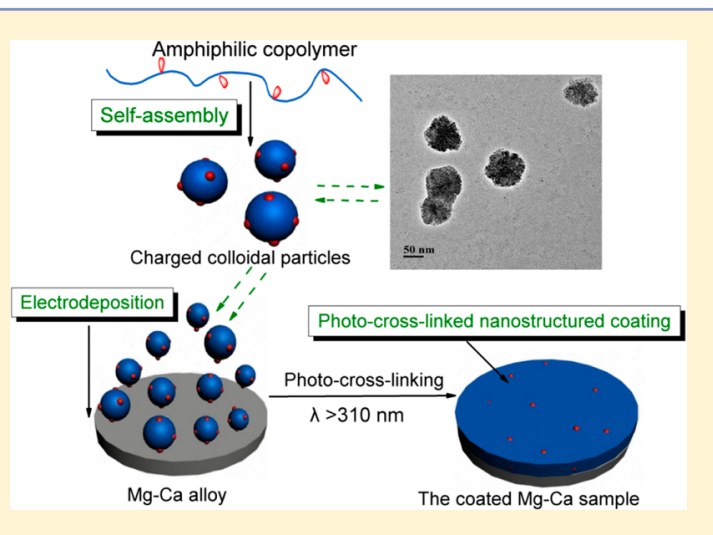
ties. More importantly, the corrosion resistance was further enhanced by chemical photo-cross-linking. In addition, the low cytotoxicity of the coated samples was confirmed by MTT assay against NIH-3T3 normal cells. The contribution of our work lies in the creation of a novel strategy to fabricate a biomedical coating in view of the versatility of self-assembled colloidal particles and the controllability of the electrodeposition process. It is believed that our work provides new ideas and reliable data to design novel functional biomedical coatings.
\end{abstract}

\section{INTRODUCTION}

$\operatorname{Poly}(\gamma$-glutamic acid) ( $\gamma$-PGA) is a kind of bacterial-secreted polypeptide. ${ }^{1,2} \gamma$-PGA and its derivatives have been widely used in many fields, such as drug delivery, ${ }^{3}$ tissue engineering, ${ }^{4}$ and wound dressing, because of their biodegradability and biocompatibility. ${ }^{5} \gamma$-PGA has abundant free carboxyl groups that can be modified by functional groups or polymers to prepare desired polymers. $^{6-8}$ With these excellent properties of $\gamma$-PGA, it is desirable to develop various $\gamma$-PGA-based multifunctional materials for wider applications.

Self-assembly has been demonstrated to be a powerful technology to make nanoscaled particles from synthetic or natural amphiphilic polymers. ${ }^{9,10}$ As reported in previous works, amphiphilic $\gamma$-PGA derivatives can self-assemble into micellar aggregates with various morphologies, such as spheres, rods, and vesicles. ${ }^{11,12}$ The attractive advantages of these nanoparticles include a high specific surface area, green nature, nontoxicity, biodegradability, and flexibility in internal or surface functionalities. Although $\gamma$-PGA-based particles have potential applications as drug delivery, protein, gene, and vaccine carriers because of these outstanding properties, ${ }^{13-16}$ research that expands the application of $\gamma$-PGA-based particles in biomedical coating systems is lacking.
The substrates used in this work are magnesium alloys, which have physical, mechanical, and biological properties very similar to those of natural bones and are promising implant materials in clinical applications. ${ }^{17,18}$ However, the widespread use of magnesium alloys has been limited because these alloys are highly susceptible to corrosion in physiological environments, especially during the initial period of implantation. ${ }^{19,20}$ To improve these weaknesses, the application of coatings is a general strategy to delay initial degradation of the alloy. ${ }^{21}$ Accordingly, a broad range of surface modification techniques, including spincoating, ${ }^{22}$ electroless plating, ${ }^{23}$ plasma electrolytic oxidation, ${ }^{24}$ physical vapor deposition, ${ }^{25}$ spraying, ${ }^{26}$ and dipping, ${ }^{27}$ have been adopted to fabricate coatings.

In addition to all of the techniques mentioned above, electrodeposition has also obtained considerable attention for making coatings because of the controlled integration of its application and the capability to produce uniform films on regularly or irregularly shaped metal substrates at ambient temperature. ${ }^{28-31}$ Furthermore, the procedure is simple and uses

Received: March 16, 2014

Revised: $\quad$ August 22, 2014

Published: August 27, 2014 
inexpensive equipment. The formation of the coating can be controlled by the deposition time, bath concentration, and applied potential. In previous reports, however, the use of electrodeposition to prepare coatings on magnesium alloys still has been relatively infrequently explored because of the high corrosion rate of magnesium alloys in aqueous solution. Moreover, some nondegradable oxides, such as $\mathrm{Mg}(\mathrm{OH})_{2}$ and $\mathrm{MgO}$, may be produced during the procedure. ${ }^{32,33}$ In order to avoid these drawbacks, we fabricate a Mg-based biomedical coating by conducting electrodeposition in organic solution. It is another advantage of our investigation, since the magnesium alloy can maintain its original surface composition without a chemical reaction with an electrolyte during the electrodeposition procedure.

The present study attempted to fabricate a biomedical coating of $\gamma$-PGA particles on magnesium alloy by combining the techniques of polymeric self-assembly and electrodeposition. In our previous work, ${ }^{34,35}$ we used a similar approach to prepare a molecular-imprinted polymeric (MIP) sensor coating in a water system. In this study, we expand the technique to the fabrication of a biomedical coating. The entire strategy is described in Figure 1. A photosensitive amphiphilic poly $(\gamma$-glutamic acid $)-g$-7-

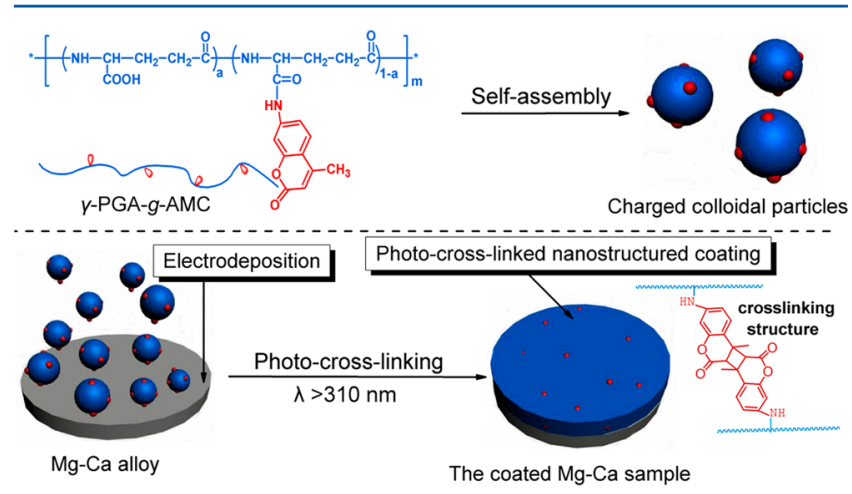

Figure 1. Schematic illustration of the magnesium-based coating fabrication using self-assembled colloidal particles and the electrodeposition technique.

amino-4-methylcoumarin ( $\gamma$-PGA-g-AMC) was prepared by modification of $\gamma$-PGA with 7-amino-4-methylcoumarin. Negatively charged colloidal particles were prepared by self-assembly of $\gamma$-PGA-g-AMC. Then the colloidal particles were deposited on the magnesium alloy to form a nanostructured coating through direct electrodeposition. To our best knowledge, this is the first example of the preparation of biomedical coatings with photosensitive $\gamma$-PGA-based particles by electrodeposition. The photosensitivity, anticorrosion properties, and cytotoxicity of the alloys were investigated in detail.

\section{EXPERIMENTAL SECTION}

2.1. Materials. $\gamma$-PGA $\left(M_{\mathrm{w}}=200000-500000\right)$ was purchased from Wako Pure Chemical Industries Co., Ltd. (Osaka, Japan). 7-Amino-4methylcoumarin (AMC), 1-ethyl-3-(3-(dimethylamino)propyl)carbodiimide hydrochloride (EDC. $\mathrm{HCl})$, and 1-hydroxybenzotriazole (HOBt) were obtained from Aladdin Reagent Co., Ltd. (Shanghai, China). Dimethyl sulfoxide (DMSO), absolute ethanol, triethylamine, and acetic acid were purchased from Sinopharm Chemical Reagent Co., Ltd. (Shanghai, China). Dulbecco's modified Eagle's medium (DMEM) (Gibco), fetal bovine serum (FBS) (Hyclone), and penicillin streptomycin (Gibco) were purchased from Wuxi Trivd Biotechnology Inc. (Wuxi, China). All of the reagents and chemicals were used without further purification.
Magnesium alloys ( $1 \mathrm{wt} \%$ Ca with the balance being $\mathrm{Mg}, 16 \mathrm{~mm}$ diameter, $1.5 \mathrm{~mm}$ thickness) were donated by Zheng and co-workers ${ }^{36}$ and used as the substrate. The magnesium plates were ground with no. 1200 abrasive paper and ultrasonically cleaned with ethanol and acetone for $10 \mathrm{~min}$.

2.2. Preparation of $\gamma$-PGA-g-AMC Copolymer. The photosensitive $\gamma$-PGA-g-AMC copolymer was prepared as follows: $\gamma$-PGA (1 unit mmol) was dissolved in $40 \mathrm{~mL}$ of DMSO by stirring and gently heating to $70{ }^{\circ} \mathrm{C}$ for $2 \mathrm{~h}$, and then the solution was cooled to room temperature. $\mathrm{EDC} \cdot \mathrm{HCl}(1 \mathrm{mmol}), \mathrm{HOBt}(2 \mathrm{mmol})$, and AMC (2 $\mathrm{mmol}$ ) were added. The reaction mixture was kept at room temperature for $24 \mathrm{~h}$. The resultant $\gamma$-PGA- $g$-AMC copolymer was purified by dialysis (molar mass cutoff 14000 ) against water to remove unreacted chemicals and DMSO. Finally, the washed $\gamma$-PGA-g-AMC copolymer was frozen and lyophilized. The purified copolymer was characterized by ${ }^{1} \mathrm{H}$ NMR spectroscopy to determine the degree of grafting of AMC.

2.3. Preparation and Characterization of Colloidal Particles. $\mathrm{UV}$-vis measurements were used to determine the content of ethanol as a precipitating agent, which was added in order to induce the selfassembly process of colloidal particles. The colloidal particles were prepared as follows: $\gamma$-PGA-g-AMC copolymers were dissolved in DMSO, forming solutions with different initial concentrations of $\gamma$ PGA-g-AMC $\left(2,3,5,8\right.$, and $\left.10 \mathrm{mg} \mathrm{mL}^{-1}\right)$. Then absolute ethanol was dropwise added into the above solutions at a rate of $20 \mu \mathrm{L} / \mathrm{min}$ to yield translucent solutions. The resulting translucent solutions were dialyzed against ethanol for 3 days to remove the DMSO solvent, and then the colloidal particle solutions $\left(0.33,1.00,1.66,2.66\right.$, and $\left.3.33 \mathrm{mg} \mathrm{mL}^{-1}\right)$ were obtained. The concentrations of the colloidal particle solutions were calculated using the original mass of the copolymer divided by the resulting particle solution volume.

Since the colloidal particles contain many carboxyl groups, which easily respond to $\mathrm{pH}$, the effect of $\mathrm{pH}$ on the particle size and surface charge was investigated. Acetic acid and triethylamine were used to adjust the $\mathrm{pH}$ of the $\gamma$-PGA- $\mathrm{g}$-AMC colloidal particle solutions, and the $\mathrm{pH}$ values were determined using a $\mathrm{pH}$ instrument (Metrohm, Shanghai Nano Instrument Co., Ltd).

UV light $(\lambda>310 \mathrm{~nm}$; a spot UV curing system with an intensity of $200 \mathrm{~W}$ ) was utilized to irradiate the colloidal particle solution $(30 \mathrm{~mL})$, preparing photo-cross-linked colloidal particles. At predetermined time intervals of UV irradiation, $5 \mathrm{~mL}$ of particle solution was collected from the original sample, and the particle size was determined.

TEM images of colloidal particles were obtained using a JEOL JEM2100 transmission electron microscope with an accelerating voltage of $200 \mathrm{kV}$. The TEM samples were prepared by dipping the copper grids into colloidal particle solution and then drying the grids at room temperature.

The particle size and its size distribution were characterized by dynamic light scattering (DLS) with ALV-5000/E DLS software (ALV/ DLS/SLS-5000, Germany) at a fixed scattering angle of $90^{\circ}$. The size distributions of the colloidal particles are reported by the scattering intensity of the particle fraction, and the measurement was conducted three times for each sample. All of the particle solutions were filtered using $0.8 \mu \mathrm{m}$ Millipore filters to remove dust before the DLS measurements.

The surface charge of the colloidal particles was measured by electrophoretic mobility measurements with a BIC PALS zeta potential analyzer (Brookhaven Instruments Corp., USA). The measurement for each sample was conducted at least five times, and each time contained 20 cycles. The results are indicated as mean \pm standard deviation (SD).

2.4. Electrodeposition of Colloidal Particles. The concentrations of the 0.33 and $1.00 \mathrm{mg} \mathrm{mL}^{-1}$ colloidal particle samples were too low to conduct electrodeposition. The $1.66,2.66$, and $3.33 \mathrm{mg} \mathrm{mL}^{-1} \gamma$ PGA-g-AMC particle solutions were used as electrolytes for electrodeposition. A small amount of triethylamine was added to control the $\mathrm{pH}$ of the electrolyte at approximately 7.5 in order to promote the deprotonation of the $-\mathrm{COOH}$ group. The magnesium alloy was used as the working electrode (anode), and a Pt electrode was used as the counter electrode (cathode). After electrodeposition was carried out at $150 \mathrm{~V}$ for $30 \mathrm{~min}$, the magnesium alloys were covered with the nanostructured coating. Then the photo-cross-linked surface was 
fabricated by UV irradiation of the coated sample for $1.5 \mathrm{~h}$ on each side (UV light was generated by a spot-curing system with a wavelength of $365 \mathrm{~nm}$ and a power of $200 \mathrm{~W}$ ). The coated samples were marked as coated-Mg-CP ${ }_{1.66}$, coated-Mg- $\mathrm{CP}_{2.66}$, and coated-Mg- $\mathrm{CP}_{3.33}$.

2.5. Physical and Chemical Properties of the Coatings. The surface morphologies of the obtained samples were determined by scanning electron microscopy (SEM) at $2.0 \mathrm{kV}$ (model S-4800, Hitachi, Tokyo, Japan). X-ray photoelectron spectroscopy (XPS) (PerkinElmer, Waltham, MA, USA), and attenuated total reflectance Fourier transform infrared spectroscopy (ATR-FTIR) (Nicolet 6700, Thermo Electron Corp., Madison, WI, USA) were used to investigate the chemical composition of the coatings. The phase compositions of the prepared samples were studied by X-ray diffraction (XRD), and the instrument (D8, Bruker, Karlsruhe, Germany) was operated from $3^{\circ}$ to $90^{\circ}$ in steps of $0.02^{\circ}$ at a scan rate of $4 \mathrm{deg} \mathrm{min}^{-1}$.

2.6. Corrosion Resistance of the Coating. Electrochemical tests were performed to evaluate the anticorrosion properties of the colloidal particle coating and bare magnesium alloys in simulated body fluid (SBF) at $37 \pm 0.5^{\circ} \mathrm{C}$. The constituents of the SBF solution were the same as in a previous report. ${ }^{37} \mathrm{~A}$ three-electrode cell was used to carry out the measurements. The sample, a platinum plate, and a saturated calomel electrode (SCE) were used as the working, counter, and reference electrodes, respectively. The scanning range was from -0.6 to $0.6 \mathrm{~V}$ of the open-circuit potential at a rate of $1 \mathrm{mV} \mathrm{s}^{-1}$.

2.7. Cytotoxicity Tests. NIH-3T3 normal cells (a mouse embryonic fibroblast cell line) were cultivated in sterile tissue culture flasks containing DMEM supplied with $10 \%$ FBS and $1 \%$ penicillin streptomycin at $37{ }^{\circ} \mathrm{C}$ in a humidified atmosphere containing $5 \% \mathrm{CO}_{2}$, and the cells were passaged by trypsinization before confluence. Cells at the third to seventh passage were used in these experiments.

These measurements were carried out using an indirect method in which the immersion extracts were used to culture cells. ${ }^{38}$ Before the measurements, bare $\mathrm{Mg}-\mathrm{Ca}$ alloys were sterilized under UV light for 1.5 $\mathrm{h}$ on each side, and the coated samples were sterilized under UV light during the cross-linking process. The immersion extracts were collected from $10 \mathrm{~mL}$ of extraction medium (DMEM) in a humidified atmosphere with $5 \% \mathrm{CO}_{2}$ at $37^{\circ} \mathrm{C}$ on day $2 . \mathrm{NIH}-3 \mathrm{~T} 3$ cells were seeded into 96 -well plates with a density of $6 \times 10^{3}$ cells per well in $100 \mu \mathrm{L}$ of medium. After 1 day of incubation, the culture medium was removed and replaced with $100 \mu \mathrm{L}$ of supplemented immersion extracts. The cells were cultured for another 2 days in a humidified atmosphere with $5 \% \mathrm{CO}_{2}$ at $37^{\circ} \mathrm{C}$. In addition, cells cultured in wells with DMEM served as control groups in this study. ${ }^{36}$

The morphologies of the cells were visualized using an inverted optical microscope (CKX41, Olympus America Inc., Center Valley, PA, USA). For each sample, images were taken at least from three to six different locations to obtain an overview of the cell attachments. Then $10 \mu \mathrm{L}$ of $5 \mathrm{mg} \mathrm{mL}^{-1}$ MTT assay stock solution in phosphate-buffered saline was added to each well of the culture plate. After the cells were incubated for $4 \mathrm{~h}$, blue formazan crystals were formed and dissolved in $100 \mu \mathrm{L}$ of DMSO per well. The absorbance was measured with a multimode detector (Tecan Infinite M200 PRO, Shanghai DoBio Biotech Co., Ltd) at a wavelength of $570 \mathrm{~nm}$. The cell viability was calculated using following equation: cell viability $=\left(\mathrm{OD}_{\text {experimental }} /\right.$ $\left.\mathrm{OD}_{\text {control }}\right) \times 100 \%$.

The per-sample MTT experiments were performed independently in quadruplicate, and three replicates were tested for each experimental point. The data were expressed as mean $\pm \mathrm{SD}$. The statistical analysis was based on one-way analysis of variance using Origin 8.6 software, and a $p$ value of less than 0.05 was considered to be statistically significant.

\section{RESULTS AND DISCUSSION}

3.1. Preparation of $\gamma$-PGA-g-AMC Copolymer. AMC was grafted to $\gamma$-PGA chains through the reaction between carboxylic groups on the linear $\gamma$-PGA chains and the amino groups of AMC. In our work, $\mathrm{EDC} \cdot \mathrm{HCl}$ and $\mathrm{HOBt}$ were used to activate carboxylic groups, which were then attached to the amino groups of AMC to produce the $\gamma$-PGA-g-AMC copolymer. The ${ }^{1} \mathrm{H}$ NMR spectrum of the resulting copolymer is shown in Figure $S 1$ in the Supporting Information. The degree of grafting was calculated by comparing the peak areas of aromatic ring protons in the coumarin group and $\mathrm{CH}$ protons in the PGA main chain; ${ }^{39}$ the results showed that nearly $20 \%$ of AMC was grafted to the $\gamma$ PGA chains.

3.2. Self-Assembly of Colloidal Particles. To prepare the self-assembled colloidal particles, absolute ethanol was gradually added dropwise to $\gamma$-PGA-g-AMC copolymer solutions. The changes in the absorbance of the different solutions were studied using UV-vis measurements. The morphology of colloidal particles in the dried state was observed by TEM.

Figure 2 shows the absorbance changes when ethanol was added to the $\gamma$-PGA-g-AMC solutions. As the results show, the

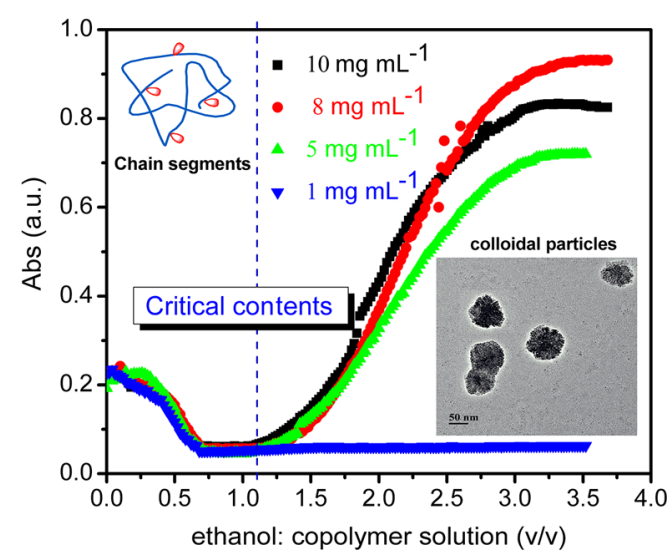

Figure 2. Changes in absorbance of $\gamma$-PGA-g-AMC solutions against ethanol content for different initial copolymer concentrations at $\lambda=621$ $\mathrm{nm}$. The inset is the TEM image of a $1.66 \mathrm{mg} \mathrm{mL}^{-1}$ colloidal particle sample that was fabricated by adding ethanol to $5 \mathrm{mg} \mathrm{mL}^{-1}$ copolymer solution (ethanol/copolymer solution $=2: 1 \mathrm{v} / \mathrm{v}$ ) and then dialyzing in ethanol for 3 days to remove the copolymer solvent DMSO.

absorbance of all of the samples initially decreased with increasing ethanol amount because the copolymer solutions were diluted by the addition of ethanol. When the ethanol content attained a certain value, the absorbance began to increase, indicating that the $\gamma$-PGA-g-AMC copolymer chains started to aggregate and form self-assembled particles, except for the sample with an initial copolymer concentration of $1 \mathrm{mg}$ $\mathrm{mL}^{-1}$, as the driving force for the self-assembly in the $1 \mathrm{mg} \mathrm{mL}^{-1}$ sample was too low to form colloidal particles. The ethanol content at this point is defined as the critical ethanol content (CEC). After the addition of more ethanol, the absorbance continued to increase because of the aggregation of selfassembled particles. In order to make a uniform distribution of colloidal particles, twice the volume equivalent of ethanol with respect to the initial copolymer solution was used to make the self-assembled colloidal particles. In the self-assembly process, the driving force is mainly related to the amount of precipitating agent (ethanol) added and the initial copolymer concentration. Since the concentration of $1 \mathrm{mg} \mathrm{mL}^{-1}$ is dilute, the interaction and chain entanglement between the copolymer segments are very weak compared with other higher concentrations. Therefore, when ethanol was added, the copolymer chain could not aggregate effectively and form particles.

The morphology and size of colloidal particles in the dried state were observed by TEM. As shown by the picture in the Figure 2 inset, the self-assembly of $\gamma$-PGA-g-AMC occurred and the aggregated colloidal particle size was almost $100 \mathrm{~nm}$ in the 
dried state. Compared with the size determined by DLS $\left(R_{\mathrm{h}}=\right.$ $115.6 \mathrm{~nm}$ at $1.66 \mathrm{mg} \mathrm{mL}^{-1}$; see Figure 3), the TEM results show a smaller particle size. This result is understandable because the swelling of the particles in solution comes from the larger amount of absorbed solvent. As solvent is evaporated, the particles would shrink. These results imply that adding ethanol as a precipitating agent could induce self-assembly of the $\gamma$-PGA- $g$-AMC copolymer. The mechanism can be explained as follows: the copolymer molecular chains contain abundant $-\mathrm{COOH}$ groups, which attract each other by hydrogen bonding, ${ }^{40}$ thus decreasing their affinity for ethanol. When precipitating agent is added, the chain segments containing-COOH groups start to collapse into insoluble complexes because of interpolymer hydrogen bonding. ${ }^{41,42}$ However, those containing $-\mathrm{COO}^{-}$groups experience mutual electrostatic repulsion and are mainly distributed in the shell of resulting particles during the process of ethanol addition, thus forming stable colloidal particles.

3.3. Effect of Initial Copolymer Concentration and $\mathrm{pH}$. Self-assembly is a dynamic equilibrium process. The polymer concentration can affect the interaction of macromolecular chains and the aggregate degree of self-assembled particles in the resulting colloidal particles. As shown in Figure 3, the average

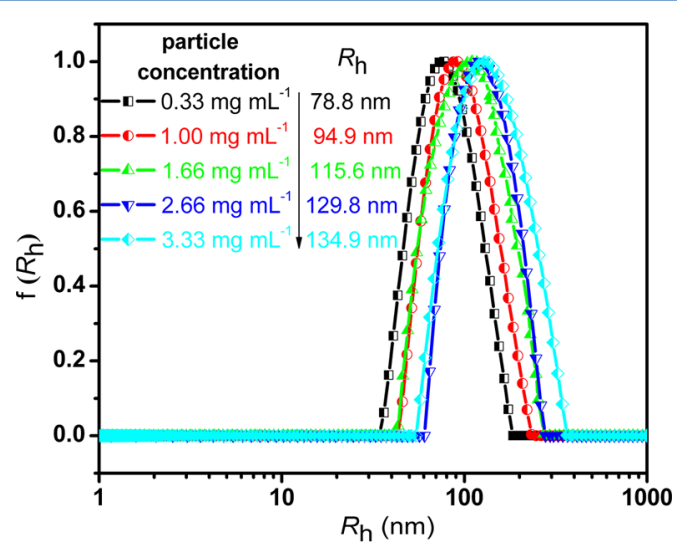

Figure 3. Average sizes and size distributions of 0.33, 1.00, 1.66, 2.66, and $3.33 \mathrm{mg} \mathrm{mL}^{-1}$ colloidal particles fabricated from 2, 3, 5, 8, and $10 \mathrm{mg}$ $\mathrm{mL}^{-1}$ initial $\gamma$-PGA-g-AMC copolymer solutions, respectively.

hydrodynamic radii $\left(R_{\mathrm{h}}\right)$ of $0.33,1.00,1.66,2.66$, and $3.33 \mathrm{mg}$ $\mathrm{mL}^{-1}$ colloidal particles increase from 78.8 to $134.9 \mathrm{~nm}$ with increasing initial concentration of $\gamma$-PGA-g-AMC from 2 to 10 $\mathrm{mg} \mathrm{mL} \mathrm{L}^{-1}$. This implies that the particle size can be controlled by adjusting the initial concentration of the copolymer solution. As the initial concentration of the copolymer solution increases, the interaction and chain entanglement between copolymer chains should also increase, and thus, more copolymer chains would be entrapped in each particle during the self-assembly process. In addition, a higher copolymer concentration induces higher particle content, and the aggregate degree of self-assembled particles in the resulting colloidal particles would increase in the self-assembly process. Therefore, increasing the concentration of the copolymer can increase the size of the self-assembled colloidal particles.

As $\gamma$-PGA- $g$-AMC colloidal particles contain plenty of carboxyl groups, which easily respond to $\mathrm{pH}$, the effect of $\mathrm{pH}$ on the particle size and surface charge was investigated. Figure 4 shows the variations of surface charge and average $R_{\mathrm{h}}$ of colloidal particles as a function of $\mathrm{pH}$. Obviously, the surface charge became more negative with increasing $\mathrm{pH}$ from 6 to 10 . As the $\mathrm{pH}$ increased from 6 to 9.5 , the average $R_{\mathrm{h}}$ increased from 95.5 to

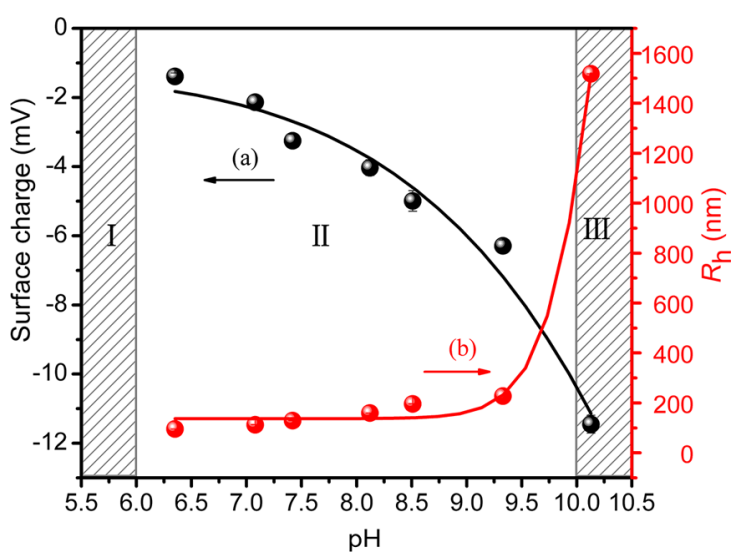

Figure 4. Effect of $\mathrm{pH}$ on (a) the surface charge and (b) the average hydrodynamic radius of the colloidal particles. The concentration of the particle solution was $1.66 \mathrm{mg} \mathrm{mL}^{-1}$.

$227.3 \mathrm{~nm}$, and then the particle size dramatically increased for $\mathrm{pH}$ $>9.5$. These results indicate that the particle size and surface charge in ethanol are both influenced by the $\mathrm{pH}$ of the solution. In our work, the self-assembled colloidal particles can keep their particle state at $\mathrm{pH} 6-10$. For $\mathrm{pH}<6$, the samples formed precipitates as a result of protonation of $-\mathrm{COO}^{-}$groups. For $\mathrm{pH}$ $>10$, the solutions became transparent, demonstrating that the particles changed into soluble molecular chains or a random coil state. These results demonstrate that electrodeposition of colloidal particles can be conducted at $\mathrm{pH} 6-10$ in order to fabricate the nanostructured coating.

3.4. Photoresponsive Properties. It is well-known that direct irradiation $(\lambda>310 \mathrm{~nm})$ of coumarin and its derivatives leads to photochemical dimerization. ${ }^{43,44}$ Because the colloidal particles contain many coumarin units that are photoresponsive to alternative irradiation with UV light, the photo-cross-linking properties of coumarin are expected to be reflected in the selfassembled particles. To monitor this property, the photosensitivity of the colloidal particles was demonstrated using DLS.

As shown in Figure 5, with increasing irradiation time (365 $\mathrm{nm}$, total intensity $200 \mathrm{~W}, 4 \mathrm{~mL}$ of solution), $R_{\mathrm{h}}$ decreased from 115.6 to $71.3 \mathrm{~nm}$. The photoinduced decrease in average $R_{\mathrm{h}}$ due to photo-cross-linking is around 52\%. It is implied that under UV irradiation, the interchain photo-cross-linking leads to shrinkage of whole colloidal particles. A similar diameter-decreasing

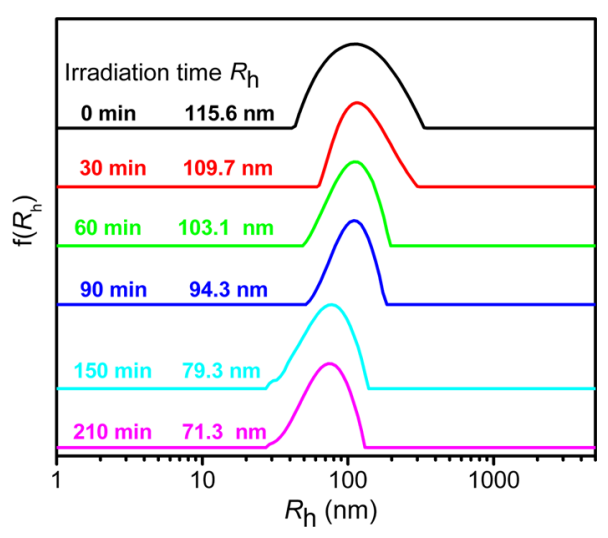

Figure 5. Hydrodynamic radius and distribution of the colloidal particles irradiated with a spot curing system $(200 \mathrm{~W}, 365 \mathrm{~nm})$ at different times. The concentration of the colloidal particle solution was $1.66 \mathrm{mg} \mathrm{mL}^{-1}$. 

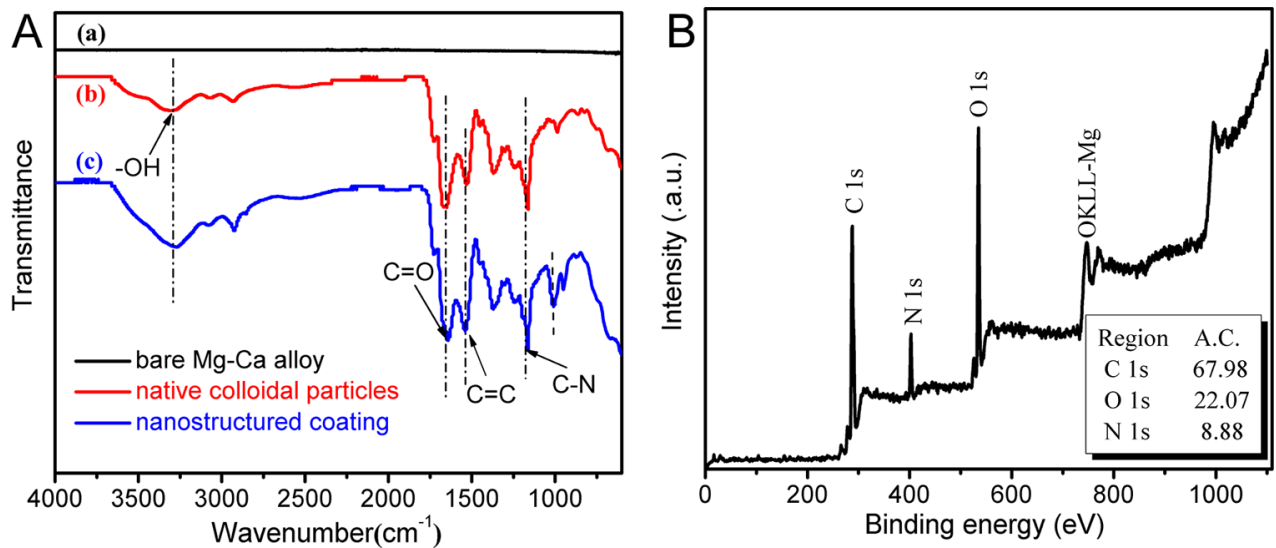

Figure 6. (A) ATR-FTIR spectra of (a) bare $\mathrm{Mg}-\mathrm{Ca}$ alloy, (b) native colloidal particles, and (c) the nanostructured coating on the Mg-Ca alloy. (B) XPS survey spectrum of the coated-Mg- $\mathrm{CP}_{1.66}$ sample.

phenomenon has also been obtained in other coumarincontaining self-assembled systems. ${ }^{45,46}$ It is believed that this photo-cross-linking property of the particles can also affect the properties of coating systems. As reported in previous work, ${ }^{47}$ UV cross-linking of colloidal particles at the oil-water interface can make a dense shell of colloidosomes and lock the interfacial particles in a Pickering or Mickering emulsion. Thus, we hypothesize that when the photo-cross-linkable colloidal particles are electrodeposited on the $\mathrm{Mg}-\mathrm{Ca}$ alloy surface, a dense coating surface can be fabricated by further UV irradiation of the electrodeposited particles.

3.5. Electrodeposition of Colloidal Particles. $\gamma$-PGA is a naturally biodegradable and nontoxic biomaterial. It consists of alternating units of D-glutamic acid and L-glutamic acid. ${ }^{48}$ The negative charge of the $\gamma$-PGA colloidal particles in solution is attributed to deprotonated $-\mathrm{COOH}$ groups. ${ }^{49}$ The nanostructured coating on the magnesium alloy can be obtained by anodic electrodeposition in ethanol. The proposed mechanism of coating formation is based on the classical DerjaguinLandau-Verwey-Overbeek (DLVO) theory of colloidal stability. ${ }^{50,51}$ This theory states that the total pair interaction between colloidal particles consists of two parts, the Coulombic double-layer repulsion and the van der Waals attraction. As reported by Lyklema, ${ }^{52}$ these forces promote the stability of colloidal particles in nonaqueous media. The DLVO theory describes the potential energy curve for pair interaction, as shown in Figure S2 in the Supporting Information. We can assume that coagulation of the colloidal particles would occur when the energy barrier is overcome. When an electric field is applied, the negatively charged $\gamma$-PGA-g-AMC colloidal particles would migrate, and this migration can induce a particle concentration gradient around the magnesium alloy surface. As determined by previous work, ${ }^{53}$ the potential energy peak decreases as the electrolyte concentration increases, and thus, there exists a critical electrolyte concentration (flocculation value) for coagulation in an applied electric field. While the energy barrier between colloidal particles disappears around the $\mathrm{Mg}-\mathrm{Ca}$ anode in the applied field, coagulation becomes possible and the nanostructured coating forms. As shown in Figure S3a-c in the Supporting Information, some particles are immobilized onto the substrate at short deposition times. This behavior indicates that charged colloidal particles can move toward the anode in the electric field within a given time. After $15 \mathrm{~min}$, the nanostructured surface was formed as a result of accumulation of colloidal particles (Figure S3d). This demonstrates that coating formation can be controlled by electrodeposition.

FTIR and XPS were used to confirm the presence of nanostructured coatings on the $\mathrm{Mg}-\mathrm{Ca}$ alloy. In the FTIR spectrum of the nanostructured coating (spectrum $\mathrm{c}$ in Figure $6 \mathrm{~A}$ ). The characteristic peak at $3258 \mathrm{~cm}^{-1}$ is related to $\mathrm{O}-\mathrm{H}$ stretching vibrations of $-\mathrm{COOH}$ groups. The peaks at 1725 and $1645 \mathrm{~cm}^{-1}$ are attributed to $\mathrm{C}=\mathrm{O}$ stretching vibrations of the $-\mathrm{COOH}$ and $-\mathrm{CO}-\mathrm{NH}-$ groups, respectively. The observed band at $1545 \mathrm{~cm}^{-1}$ is assigned to $\mathrm{C}=\mathrm{C}$. The peak at $1155 \mathrm{~cm}^{-1}$ is attributed to $\mathrm{C}-\mathrm{N}$ stretching. These bands are well in accordance with vibrational peaks of native colloidal particles (spectrum b in Figure 6A). As expected, no such peaks are seen on bare metal substrates devoid of the nanostructured coating (spectrum a in Figure 6A). Moreover, the observed band at 1006 $\mathrm{cm}^{-1}$ in the FTIR spectrum of the nanostructured coating is related to the absorption of triethylamine. The XPS results imply that main elements on the surface of the coated sample are $C, N$, and $\mathrm{O}$ (Figure 6B). The results indicate the formation of nanostructured coatings on the surface of magnesium alloys.

The surface microstructure of the coated samples was investigated by SEM (Figure 7). The results show that the morphologies of the nanostructured coatings are uniform, and some colloidal particles can be clearly seen before UV irradiation (Figure 7A1-C1). This indicates that homogeneous nanostructured coatings are fabricated by electrodeposition of selfassembled colloidal particles. After UV irradiation for $1.5 \mathrm{~h}$, the surfaces of the cross-linked coatings (Figure 7A2-C2) are denser and smoother as a result of the photo-cross-linking properties of self-assembled particles. Photo-cross-linking of the particles is demonstrated to improve the homogeneity and also the sealability of the nanostructured coating. Generally, a denser coating on the magnesium alloy provides better physiological corrosion resistance of the substrate. Therefore, photo-crosslinking of the nanostructured coating supposedly contributes to the anticorrosion performance of the magnesium alloy, and we will discuss this topic in detail in section 3.7.

3.6. XRD Analyses of the Coated Samples. The XRD patterns of the bare and coated magnesium alloys are shown in Figure 8 . The intensity of the $\mathrm{Mg}$ phase of the bare substrate (curve a) is very strong. As the concentration of the colloidal particle electrolyte for electrodeposition increases, the intensity of the $\mathrm{Mg}$ phase of the coated sample decreases accordingly (curves $b-d$ ). The increase in the electrolyte concentration is suggested to result in the increase in deposited mass. In addition, 


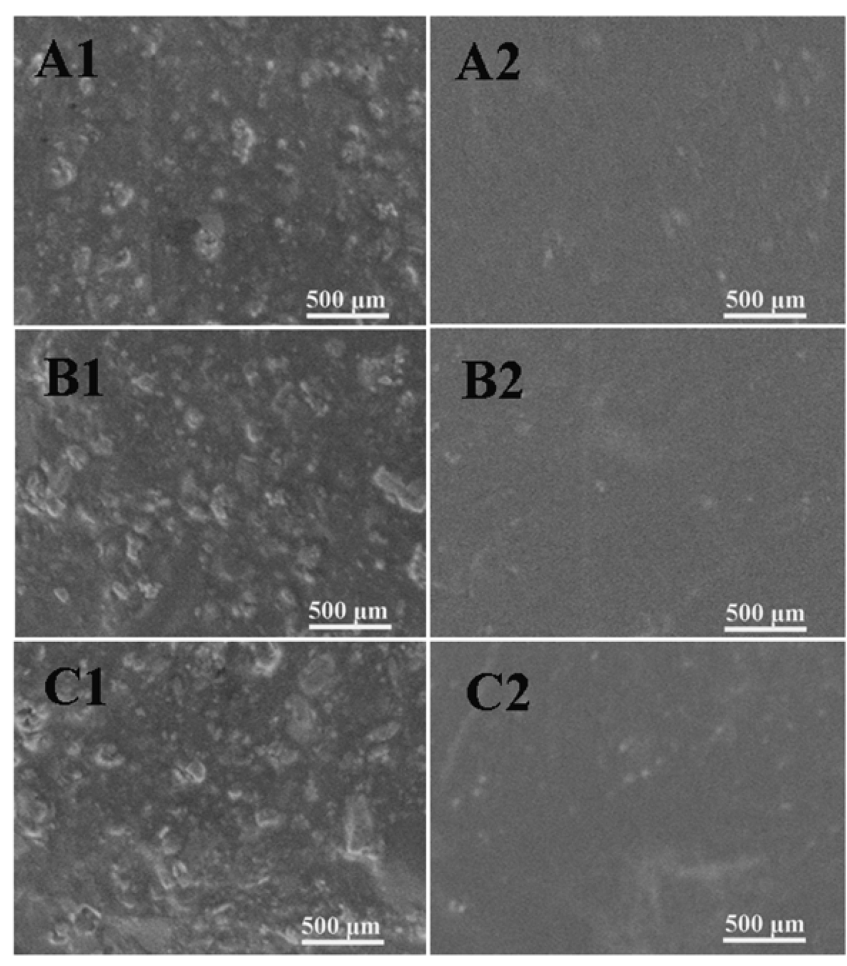

Figure 7. SEM images of the coated magnesium samples [(A1) coated$\left.\mathrm{Mg}-\mathrm{CP}_{1.66} ; \mathrm{B} 1\right)$ coated-Mg- $\mathrm{CP}_{2.66} ;(\mathrm{C} 1)$ coated-Mg- $\left.\mathrm{CP}_{3.33}\right]$ and photocross-linked samples [(A2) coated-Mg- $\mathrm{CP}_{1.66} ;$ (B2) coated-Mg-CP ${ }_{2.66}$; (C2) coated-Mg-CP $\left.{ }_{3.33}\right]$. The photo-cross-linking time was $1.5 \mathrm{~h}$ with a spot curing system $(200 \mathrm{~W}, 365 \mathrm{~nm})$ on each side.

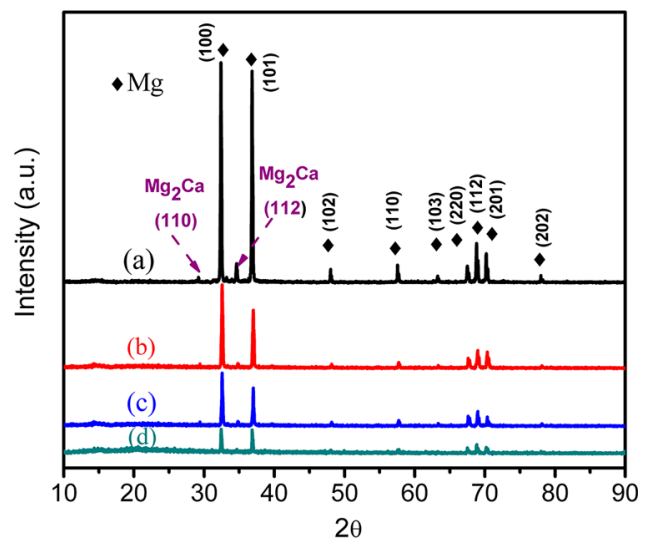

Figure 8. XRD patterns of (a) bare magnesium alloy, (b) coated-Mg$\mathrm{CP}_{1.66}$, (c) coated-Mg- $\mathrm{CP}_{2.66}$, and (d) coated-Mg- $\mathrm{CP}_{3.33}$.

the phases of oxides, such as $\mathrm{Mg}(\mathrm{OH})_{2}$ and $\mathrm{MgO}$, are not observed in the XRD patterns. This result implies that nonbiodegradable oxides are barely formed in our organic systems. Furthermore, similar experiments were also performed in water systems, and the $\mathrm{Mg}(\mathrm{OH})_{2}$ phase was observed in the XRD patterns (Figure S4 in the Supporting Information). These results obviously identify that the original properties of the magnesium alloys are maintained throughout the electrodeposition process in our organic systems. This observation is good news for magnesium alloys as implant materials because non-biodegradable oxides are not formed and the original biocompatibility and biodegradability of the magnesium alloys have been protected.
3.7. Corrosion Properties of Samples. The protective properties of the coatings were evaluated through potentiodynamic polarization tests in SBF: the more positive the corrosion potential $\left(E_{\text {corr }}\right)$ (or the lower the polarization current), the better the corrosion resistance. Generally, the cathodic polarization curves are assumed to represent cathodic hydrogen evolution through water reduction, whereas the anodic polarization curves represent the dissolution or destruction behaviors of the protective coating. ${ }^{54}$

As shown in Figure $S 5$ in the Supporting Information, $E_{\text {corr }}$ for the nanostructured-coating-modified sample is more positive than that for the bare magnesium alloy. The corrosion current density $\left(I_{\text {corr }}\right)$ of the coated magnesium alloy correspondingly decreases. In addition, the corrosion resistance is further enhanced by $1.5 \mathrm{~h}$ of UV irradiation because photo-cross-linking induces the dense and smooth surface of the coated sample (as shown in the SEM measurements). These results indicate that photo-cross-linking of nanostructured coatings provides good corrosion resistance to the magnesium alloy.

The polarization curves for the bare magnesium alloy, coated$\mathrm{Mg}-\mathrm{CP}_{1.66}$, coated-Mg- $\mathrm{CP}_{2.66}$, and coated-Mg-CP 3.33 after $1.5 \mathrm{~h}$ of UV photo-cross-linking on each side are shown in Figure 9.

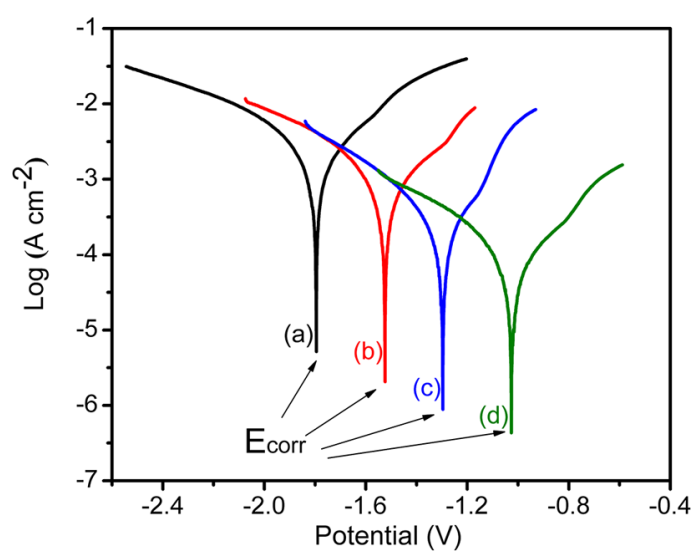

Figure 9. Polarization curves of (a) bare magnesium alloy, (b) coated$\mathrm{Mg}-\mathrm{CP}_{1.66}$, (c) coated-Mg-CP 2.66 , and (d) coated-Mg- $\mathrm{CP}_{3.33}$ in $30 \mathrm{~mL}$ of $\mathrm{SBF}$ at $37 \pm 0.5^{\circ} \mathrm{C}, \mathrm{pH} 7.4$.

Table 1. Corrosion Potential $\left(E_{\text {corr }}\right)$ and Current Density $\left(I_{\text {corr }}\right)$ Values for Uncoated and Coated Samples

\begin{tabular}{lcc}
\multicolumn{1}{c}{ sample } & $E_{\text {corr }}(\mathrm{V})$ & $I_{\text {corr }}\left(\mathrm{A} \mathrm{cm}^{-2}\right)$ \\
bare magnesium alloy & -1.80 & $8.71 \times 10^{-4}$ \\
coated-Mg-CP & -1.62 & $3.31 \times 10^{-4}$ \\
coated-Mg-CP & -1.30 & $9.98 \times 10^{-5}$ \\
coated-Mg-CP & -1.03 & $4.63 \times 10^{-5}$ \\
\hline
\end{tabular}

The $E_{\text {corr }}$ and $I_{\text {corr }}$ values are summarized in Table 1 . The results imply that all of the coatings exhibit a better protective function as reflected from their more positive $E_{\text {corr }}$ and lower $I_{\text {corr }}$ values. Compared with the value for the bare magnesium alloy $(-1.80$ $\mathrm{V}), E_{\text {corr }}$ increases by $15.6 \%$ for coated-Mg- $\mathrm{CP}_{1.66}, 27.8 \%$ for coated-Mg- $\mathrm{CP}_{2.66}$, and $42.8 \%$ for coated-Mg-CP ${ }_{3.33}$. The shift of $E_{\text {corr }}$ in the positive direction can be attributed to the protective properties provided by photo-cross-linking of the nanostructured coatings formed on magnesium alloys. $I_{\text {corr }}$ decreases by $62.0 \%, 88.5 \%$, and $94.7 \%$ for the coated-Mg- $\mathrm{CP}_{1.66}$, coated-Mg- 

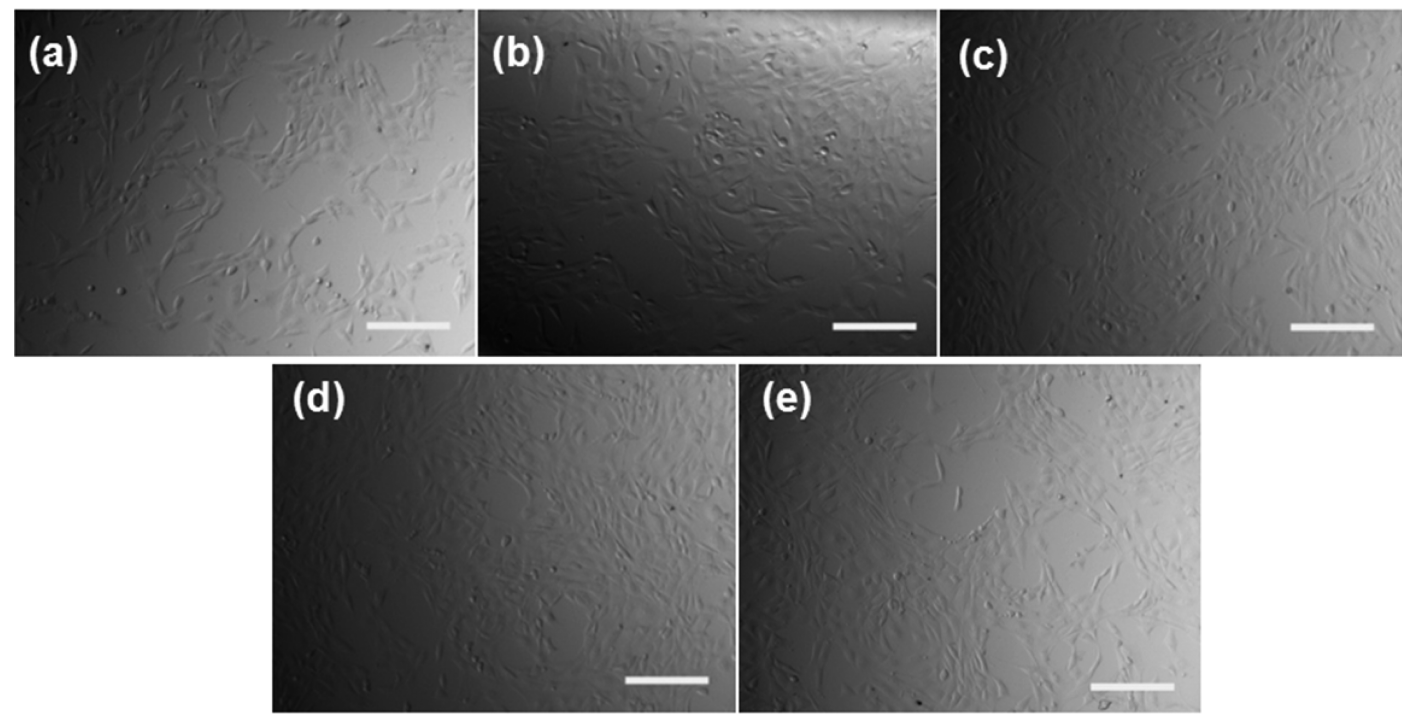

Figure 10. Light microscope images of NIH-3T3 cells: (a) bare $\mathrm{Mg}-\mathrm{Ca}$ alloy; (b) coated-Mg-CP ${ }_{1.66}$; (c) coated-Mg-CP $\mathrm{C}_{2.66}$; (d) coated-Mg-CP ${ }_{3.33}$; (e) control group. The scale bars are $200 \mu \mathrm{m}$.

$\mathrm{CP}_{2.66}$, and coated-Mg- $\mathrm{CP}_{3.33}$ samples, respectively. These results illustrate that the protective properties of the nanostructured coatings can be adjusted by controlling the concentration of the colloidal particle electrolyte in the electrodeposition process. These results support the conclusion that nanostructured coatings fabricated by electrodeposition of the colloidal particle electrolyte can act as protective layers and improve the initial anticorrosion properties of magnesium alloy substrates in an SBF environment.

3.8. Cytotoxicity Assay. The morphology of NIH-3T3 cells was examined by inverted optical microscopy with a digital camera. Figure 10 shows that viable cells were observed on culturing plates after 2 days, and higher magnification images are shown in Figure S6 in the Supporting Information. Compared with the control group, the majority of NIH-3T3 cells cultured in the medium with immersion extracts exhibit a healthy morphology of cells with an elongated and flattened spindle shape. More importantly, the cells cultured with immersion extracts of the coated samples show good cell spread and cell densities in contrast to those of the uncoated one, suggesting that better cytocompatibility is obtained with coated magnesium alloys.

The cell viability for different samples was evaluated by the MTT assay using NIH-3T3 cells through an indirect method in which immersion extracts were used to conduct the assay. The MTT assay is based on the ability of a mitochondrial dehydrogenation enzyme in viable cells to cleave the tetrazolium rings of paleyellow MTT and form formazan crystals with a dark-blue color. ${ }^{55}$

Figure 11 shows cell viability after 2 days of incubation with immersion extracts of uncoated and coated $\mathrm{Mg}-\mathrm{Ca}$ samples; the group cultured in DMEM without immersion extracts was used as a control. The results demonstrate that cells cultured in the extracts show significant differences $(p<0.05)$ in the average cell viability relative to the control. Also, all of the extracts of coated samples $(\mathrm{c}-\mathrm{e})$ were well-tolerated by the NIH-3T3 cells with average cell viabilities ranging from nearly $112.2 \%$ to $151.5 \%$, in contrast to that of control group. Instead, the cells cultured with immersion extracts of uncoated $\mathrm{Mg}-\mathrm{Ca}$ alloy showed relatively low viability. Therefore, all of the coated samples exhibited low cytotoxicity toward NIH-3T3 cells, revealing improved cytocompatibility after surface treatment. As reported by previous

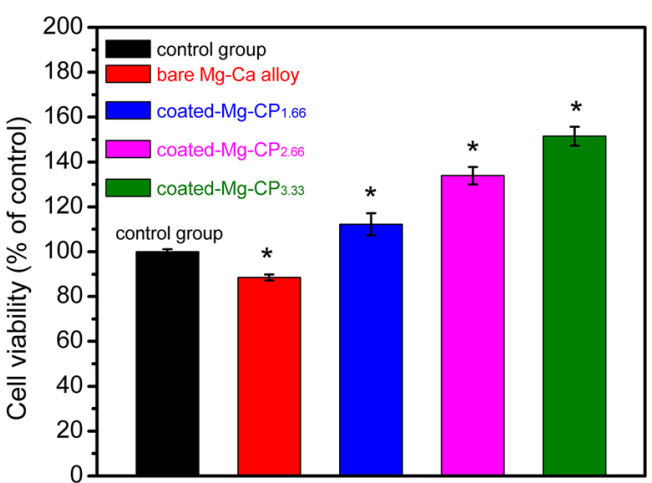

(a)

(b)

(c)

(d)

(e)

Figure 11. Cell viability of NIH-3T3 cells after culturing for 2 days with different immersion extracts and control group: (a) control group; (b) bare $\mathrm{Mg}-\mathrm{Ca}$ alloy; (c) coated-Mg-CP ${ }_{1.66}$; (d) coated-Mg-CP $\mathrm{C}_{2.66}$; (e) coated-Mg- $\mathrm{CP}_{3.33}$. Values are expressed as mean $\pm \mathrm{SD}(n=4)$. Asterisks (*) denote statistically significant differences at $p<0.05$ vs the control.

work, ${ }^{56}$ the viability of cells grown in extracts is strongly correlated with the corrosion products of the magnesium alloy sample. The main corrosion products of immersion extracts used in the cell experiment are $\mathrm{Mg}^{2+}$ and $\mathrm{OH}^{-}$; the ion contents would influence the cellular ion balance, cellular metabolism, and other features, thus influencing the viability of cells. The low viability of cells cultured with immersion extracts of uncoated $\mathrm{Mg}-\mathrm{Ca}$ alloy may be caused by the damage due to higher $\mathrm{Mg}^{2+}$ and $\mathrm{OH}^{-}$ concentrations produced through the rapid corrosion process of magnesium alloy, while the higher viability of cells cultured with those of coated magnesium alloys is probably due to the fact that appropriate ion contents can promote the cellular metabolism and growth. ${ }^{57-59}$

\section{CONCLUSION}

In this work, we have presented a new and efficient way to fabricate biomedical coatings via electrodeposition of selfassembled colloidal particles of an amphiphilic photo-crosslinkable copolymer on magnesium alloys. The resulting selfassembled colloidal particles are responsive to initial copolymer concentration, $\mathrm{pH}$, and UV irradiation, as indicated by DLS 
analysis, TEM characterization, and zeta potential measurements. In addition, the obtained coatings show more favorable corrosion resistance, and the coated samples exhibit low cytotoxicity toward NIH-3T3 cells compared with bare magnesium alloy. The whole strategy, which combines the advantages of self-assembled particles and electrodeposition, is novel, simple to control, and inexpensive. More importantly, this work demonstrates a general and promising approach for the development of functional biomedical coatings for not only magnesium alloys but also a wide range of metals using in medical applications.

\section{ASSOCIATED CONTENT}

\section{S Supporting Information}

${ }^{1} \mathrm{H}$ NMR spectrum of $\gamma$-PGA-g-AMC, illustration of the electrodeposition mechanism, SEM images of nanostructured coatings obtained at different deposition times, XRD pattern of a coated sample fabricated in water solution, polarization curves of the coated-Mg- $\mathrm{CP}_{1.66}$ sample before and after UV irradiation, and higher-magnification images of NIH-3T3 cells. This material is available free of charge via the Internet at http://pubs.acs.org.

\section{AUTHOR INFORMATION}

\section{Corresponding Author}

*E-mail: lxy@jiangnan.edu.cn.

\section{Notes}

The authors declare no competing financial interest.

\section{ACKNOWLEDGMENTS}

This work was supported by the National Natural Science Foundation of China (NNSFC) (Grants 20974041 and 21174056), MOE and SAFEA for the 111 Project (B13025), and funds from the Jiangsu Postgraduate Scientific Research and Innovation Plan Project (under Grant KYLX_1128).

\section{REFERENCES}

(1) Young, H. K.; Richard, A. G. Effects of Glucose and Glycerol on $\gamma$ Poly(glutamic acid) Formation by Bacillus licheniformis ATCC 9945a. Biotechnol. Bioeng. 1998, 54, 430-437.

(2) Cromwick, A. M.; Birrer, G. A.; Gross, R. A. Effects of pH and Aeration on $\gamma$-Poly(glutamic acid) Formation by Bacillus licheniformis in Controlled Batch Fermentor Cultures. Biotechnol. Bioeng. 1996, 50, 222-227.

(3) Kuo, Y. C.; Yu, H. W. Polyethyleneimine/poly $(\gamma$-glutamic acid $) /$ poly(lactide-co-glycolide) nanoparticles for loading and releasing antiretroviral drug. Colloids Surf., B 2011, 88, 158-164.

(4) Chang, K. Y.; Cheng, L. W.; Ho, G. H.; Huang, Y. P.; Lee, Y. D. Fabrication and characterization of poly $(\gamma$-glutamic acid $)$-graftchondroitin sulfate/polycaprolactone porous scaffolds for cartilage tissue engineering. Acta Biomater. 2009, 5, 1937-1947.

(5) Tsao, C. T.; Chang, C. H.; Lin, Y. Y.; Wu, M. F.; Wang, J. L.; Young, T. H.; Han, J. L.; Hsieh, K. H. Evaluation of chitosan $/ \gamma$-poly(glutamic acid) polyelectrolyte complex for wound dressing materials. Carbohydr. Polym. 2011, 84, 812-819.

(6) Matsusaki, M.; Serizawa, T.; Kishida, A.; Endo, T.; Akashi, M. Novel Functional Biodegradable Polymer: Synthesis and Anticoagulant Activity of Poly $(\gamma$-Glutamic Acid) sulfonate ( $\gamma$-PGA-sulfonate). Bioconjugate Chem. 2002, 13, 23-28.

(7) Murakami, S.; Aoki, N. Bio-Based Hydrogels Prepared by CrossLinking of Microbial Poly $(\gamma$-glutamic acid $)$ with Various Saccharides. Biomacromolecules 2006, 7, 2122-2127.

(8) Akagi, T.; Higashi, M.; Kaneko, T.; Kida, T.; Akashi, M. Hydrolytic and Enzymatic Degradation of Nanoparticles Based on Amphiphilic Poly $(\gamma$-glutamic acid)-graft-L- Phenylalanine Copolymers. Biomacromolecules 2006, 7, 297-303.
(9) Yi, C. L.; Yang, Y. L.; Zhu, Y.; Liu, N.; Liu, X. Y.; Luo, J.; Jiang, M. Self-Assembly and Emulsification of Poly\{[styrene-alt-maleic acid]-co[styrene-alt-(N-3,4-dihydroxyphenylethylmaleamic acid)]\}. Langmuir 2012, 28, 9211-9222.

(10) Piyapakorn, P.; Akagi, T.; Hachisuka, M.; Onishi, T.; Matsuoka, H.; Akashi, M. Structural Analysis of Unimer Nanoparticles Composed of Hydrophobized Poly(amino acid)s. Macromolecules 2013, 46, 61876194.

(11) Kaneko, T.; Higashi, M.; Matsusaki, M.; Akagi, T.; Akashi, T. SelfAssembled Soft Nanofibrils of Amphipathic Polypeptides and Their Morphological Transformation. Chem. Mater. 2005, 17, 2484-2486.

(12) Akagi, T.; Piyapakorn, P.; Akashi, M. Formation of Unimer Nanoparticles by Controlling the Self-Association of Hydrophobically Modified Poly(amino acid)s. Langmuir 2012, 28, 5249-5256.

(13) Akagi, T.; Kaneko, T.; Kida, T.; Akashi, M. Preparation and characterization of biodegradable nanoparticles based on $\operatorname{poly}(\gamma$ glutamic acid) with L-phenylalanine as a protein carrier. J. Controlled Release 2005, 108, 226-236.

(14) Ryu, M.; Nakazawa, T.; Akagi, T.; Tanaka, T.; Watanabe, R.; Yasuda, M.; Himori, N.; Maruyama, K.; Yamashita, T.; Abe, T.; Akashi, M.; Nishida, K. Suppression of phagocytic cells in retinal disorders using amphiphilic poly $(\gamma$-glutamic acid $)$ nanoparticles containing dexamethasone. J. Controlled Release 2011, 151, 65-73.

(15) Shima, F.; Uto, T.; Akagi, T.; Akashi, M. Synergistic Stimulation of Antigen Presenting Cells via TLR by Combining CpG ODN and Poly $(\gamma$-glutamic acid)-Based Nanoparticles as Vaccine Adjuvants. Bioconjugate Chem. 2013, 24, 926-933.

(16) Sakuma, S.; Sagawa, T.; Masaoka, Y.; Kataoka, M.; Yamashita, S.; Shirasaka, Y.; Tamai, I.; Ikumi, Y.; Kida, T.; Akashi, M. Stabilization of enzyme-susceptible glucoside bonds of phloridzin through conjugation with poly ( $\gamma$-glutamic acid). J. Controlled Release 2009, 133, 125-131.

(17) Wu, G. S.; Ibrahim, J. M.; Chu, P. K. Surface design of biodegradable magnesium alloys-A review. Surf. Coat. Technol. 2013, $233,2-12$.

(18) Zheng, Y. F.; Gu, X. N.; Li, N.; Zhou, W. R. Development and Prospects of Biodegradable Magnesium Alloys. Mater. China 2011, 30, $30-43$.

(19) Witte, F.; Fischer, J.; Nellesen, J.; Crostack, H. A.; Pisch, V. K.; Beckmann, F.; Windhagen, $H$. In vitro and in vivo corrosion measurements of magnesium alloys. Biomaterials 2006, 27, 1013-1018.

(20) Mueller, W. D.; Nascimento, M. L.; Mele, M. F. L. Critical discussion of the results from different corrosion studies of $\mathrm{Mg}$ and $\mathrm{Mg}$ alloys for biomaterial applications. Acta Biomater. 2010, 6, 1749-1755.

(21) Hornberger, H.; Virtanen, S.; Boccaccini, A. R. Biomedical coatings on magnesium alloys-A review. Acta Biomater. 2012, 8, $2442-2455$

(22) Xu, L. P.; Yamamoto, A. Characteristics and cytocompatibility of biodegradable polymer film on magnesium by spin coating. Colloids Surf., B 2012, 93, 67-74.

(23) Lu, P.; Liu, Y.; Guo, M. Q.; Fang, H. D.; Xu, X. H. Corrosion and drug release properties of EN-plating/PLGA composite coating on MAO film. Mater. Sci. Eng., C 2011, 31, 1285-1289.

(24) Gallino, E.; Massey, S.; Tatoulian, M.; Mantovani, D. Plasma polymerized allylamine films deposited on $316 \mathrm{~L}$ stainless steel for cardiovascular stent coatings. Surf. Coat. Technol. 2010, 205, 24612468.

(25) Ishizaki, T.; Okido, M.; Masuda, Y.; Saito, N.; Sakamoto, M. Corrosion Resistant Performances of Alkanoic and Phosphonic Acids Derived Self-Assembled Monolayers on Magnesium Alloy AZ31 by Vapor-Phase Method. Langmuir 2011, 27, 6009-6017.

(26) Spencer, K.; Fabijanic, D. M.; Zhang, M. X. The use of $\mathrm{Al}_{-} \mathrm{Al}_{2} \mathrm{O}_{3}$ cold spray coatings to improve the surface properties of magnesium alloys. Surf. Coat. Technol. 2009, 204, 336-344.

(27) Conceicao, T. F.; Scharnagl, N.; Dietzel, W.; Kainer, K. U. Corrosion protection of magnesium AZ31 alloy using poly(ether imide) [PEI] coatings prepared by the dip coating method: Influence of solvent and substrate pre-treatment. Corros. Sci. 2011, 53, 338-346.

(28) Fernandes, R.; Wu, L. Q.; Chen, L. H.; Yi, H.; Rubloff, G. W.; Ghodssi, R.; Bentley, W. E.; Payne, G. F. Electrochemically Induced 
Deposition of a Polysaccharide Hydrogel onto a Patterned Surface. Langmuir 2003, 19, 4058-4062.

(29) Krylova, I. Painting by electrodeposition on the eve of the 21st century. Prog. Org. Coat. 2001, 42, 119-131.

(30) Ma, R.; Epand, R. F.; Zhitomirsky, I. Electrodeposition of hyaluronic acid and hyaluronic acid-bovine serum albumin films from aqueous solutions. Colloids Surf., B 2010, 77, 279-285.

(31) Seuss, S.; Boccaccini, A. R. Electrophoretic Deposition of Biological Macromolecules, Drugs, and Cells. Biomacromolecules 2013, 14, 3355-3369.

(32) Zhao, Q. M.; Guo, X.; Dang, X. Q.; Hao, J. M.; Lai, J. H.; Wang, K. Z. Preparation and properties of composite $\mathrm{MAO} / \mathrm{ECD}$ coatings on magnesium alloy. Colloids Surf., B 2013, 102, 321-326.

(33) Gu, X. N.; Li, N.; Zhou, W. R.; Zheng, Y. F.; Zhao, X.; Cai, Q. Z.; Ruan, L. Q. Corrosion resistance and surface biocompatibility of a microarc oxidation coating on a $\mathrm{Mg}-\mathrm{Ca}$ alloy. Acta Biomater. 2011, 7, $1880-1889$.

(34) Yang, Y. Q.; Yi, C. L.; Luo, J.; Liu, R.; Liu, J. K.; Jiang, J. Q.; Liu, X. Y. Glucose sensors based on electrodeposition of molecularly imprinted polymeric micelles: A novel strategy for MIP sensors. Biosens. Bioelectron. 2011, 26, 2607-2612.

(35) Luo, J.; Fan, C. H.; Wang, X. H.; Liu, R.; Liu, X. Y. A novel electrochemical sensor for paracetamol based on molecularly imprinted polymeric micelles. Sens. Actuators, B 2013, 188, 909-916.

(36) Li, Z. J.; Gu, X. N.; Lou, S. Q.; Zheng, Y. F. The development of binary magnesium alloys for use as biodegradable materials within bone. Biomaterials 2008, 29, 1329-1344.

(37) Alabbasi, A.; Liyanaarachchi, S.; Kannan, M. B. Polylactic acid coating on a biodegradable magnesium alloy: An in vitro degradation study by electrochemical impedance spectroscopy. Thin Solid Films 2012, 520, 6841-6844.

(38) Zhao, Y.; Jamesh, M. I.; Li, W. K.; Wu, G. S.; Wang, C. X.; Zheng, Y. F.; Yeung, K. W. K.; Chu, P. K. Enhanced antimicrobial properties, cytocompatibility, and corrosion resistance of plasma-modified biodegradable magnesium alloys. Acta Biomater. 2014, 10, 544-556.

(39) Novák, L.; Bányai, I.; Judit Éva, F. R.; Borbély, J. Direct Amidation of Poly $(\gamma$-glutamic acid) with Benzylamine in Dimethyl Sulfoxide. Biomacromolecules 2007, 8, 1624-1632.

(40) Dou, H. J.; Jiang, M.; Peng, H. S.; Chen, D. Y.; Hong, Y. pHDependent Self-Assembly: Micellization and Micelle-Hollow-Sphere Transition of Cellulose-Based Copolymers. Angew. Chem., Int. Ed. 2003, 42, 1516-1519.

(41) Cao, Y.; Shen, X. C.; Chen, Y.; Guo, J.; Chen, Q.; Jiang, X. Q.pHInduced Self-Assembly and Capsules of Sodium Alginate. Biomacromolecules 2005, 6, 2189-2196.

(42) Petka, W. A.; Harden, J. L.; McGrath, K. P.; Wirtz, D.; Tirrell, D. A. Reversible Hydrogels from Self-Assembling Artificial Proteins. Science 1998, 281, 389-392.

(43) Luo, J.; Zhou, Q.; Sun, J.; Jiang, J. Q.; Zhou, X.; Zhang, H. W.; Liu, X. Y. Photoresponsive Water-Dispersible Polyaniline Nanoparticles through Template Synthesis with Copolymer Micelle Containing Coumarin Groups. J. Polym. Sci., Part A: Polym. Chem. 2012, 50, 40374045 .

(44) Jiang, J. Q.; Shu, Q. Z.; Chen, X.; Yang, Y. Q.; Yi, C. L.; Song, X. Q.; Liu, X. Y.; Chen, M. Q. Photoinduced Morphology Switching of Polymer Nanoaggregates in Aqueous Solution. Langmuir 2010, 26, 14247-14254.

(45) Yan, B.; Boyer, J. C.; Branda, N. R.; Zhao, Y. Near-Infrared LightTriggered Dissociation of Block Copolymer Micelles Using Upconverting Nanoparticles. J. Am. Chem. Soc. 2011, 133, 19714-19717.

(46) Lv, C.; Wang, Z.; Wang, P.; Tang, X. J. Photodegradable Polyurethane Self-Assembled Nanoparticles for Photocontrollable Release. Langmuir 2012, 28, 9387-9394.

(47) Gong, Y.; Zhu, A. M.; Zhang, Q. G.; Liu, Q. L. Colloidosomes from poly ( $N$-vinyl-2-pyrrolidone $)$-coated poly $(N$-isopropylacrylamideco-acrylic acid) microgels via UV crosslinking. RSC Adv. 2014, 4, 94459450.

(48) Wei, X. T.; Ji, Z. X.; Chen, S. W. Isolation of Halotolerant Bacillus licheniformis WX-02 and Regulatory Effects of Sodium Chloride on Yield and Molecular Sizes of Poly- $\gamma$-Glutamic Acid. Appl. Biochem. Biotechnol. 2010, 160, 1332-1340.

(49) Akagi, T.; Higashi, M.; Kaneko, T.; Kida, T.; Akashi, M. In Vitro Enzymatic Degradation of Nanoparticles Prepared from Hydrophobically-Modified Poly( $\gamma$-glutamic acid). Macromol. Biosci. 2005, 5, 598602 .

(50) Zhitomirsky, I. Cathodic electrodeposition of ceramic and organoceramic materials. Fundamental aspects. Adv. Colloid Interface Sci. 2002, 97, 279-317.

(51) Sarkar, P.; Nicholson, P. S. Electrophoretic Deposition (EPD): Mechanisms, Kinetics, and Application to Ceramics. J. Am. Ceram. Soc. 1996, 79, 1987-2002.

(52) Lyklema, J. Principles of the Stability of Lyophobic Colloidal Dispersions in Non-aqueous Media. Adv. Colloid Interface Sci. 1968, 2, 65-114.

(53) Koelmans, H.; Overbeek, J. Th. G. Stability and electrophoretic deposition of suspension in non-aqueous media, discuss. Discuss. Faraday Soc. 1954, 18, 52-62.

(54) Stern, M.; Geary, A. L. Electrochemical Polarization I. A Theoretical Analysis of the Shape of Polarization Curves. J. Electrochem. Soc. 1957, 104, 56-63.

(55) Fotakis, G.; John, J. A. In vitro cytotoxicity assays: Comparison of LDH, neutral red, MTT and protein assay in hepatoma cell lines following exposure to cadmium chloride. Toxicol. Lett. 2006, 160, 171177.

(56) Wong, H. M.; Yeung, K. W. K.; Lam, K. O.; Tam, V.; Chu, P. K.; Cheung, K. L. K. A biodegradable polymer-based coating to control the performance of magnesium alloy orthopaedic implants. Biomaterials 2010, 31, 2084-2096.

(57) Feyerabend, F.; Fischer, J.; Holtz, J.; Witte, F.; Willumeit, R.; Drücker, H.; Vogt, C.; Hort, N. Evaluation of short-term effects of rare earth and other elements used in magnesium alloys on primary cells and cell lines. Acta Biomater. 2010, 6, 1834-1842.

(58) Groos, E.; Walker, L.; Masters, J. R. W. Intravesical chemotherapy: Studies on the relationship between $\mathrm{pH}$ and cytotoxicity. Cancer 1986, 58, 1199-1203.

(59) Ma, W. H.; Zhang, Y. Z. Development in physiological regulation and bone metabolism of magnesium. Chin. J. Tissue Eng. Res. 2014, 18, 432-439. 